\title{
Canada among top 20 countries for skin cancer risk
}

Cite as: CMAJ 2018 August 13;190:E971. doi: 10.1503/cmaj.109-5643

Posted on cmajnews.com on July 26, 2018.

anada ranks 19th in the world for skin cancer susceptibility, accord-

ing to an international study conducted by derma.plus, a dermatology expert group based in Germany.

The incidence of skin cancer has increased dramatically over the past decades, according to Dr. Dietrich Abeck, the group's chief medical officer. More than three million non-melanoma skin cancers and 150000 melanomas are diagnosed around the world annually. One of three cancers diagnosed is a skin cancer.

Researchers indexed the 62 countries with the highest rates of skin cancer and found that high levels of ultraviolet exposure coupled with lighter skin tones led to a larger number of new cases. New Zealand and Australia had the most new cases per population, followed by Switzerland, Sweden and Norway. Bangladesh had the fewest cases, followed by Iraq, Egypt, India and Pakistan.

However, according to Abeck, "the index reveals that countries such as New Zealand and Australia, which have some of the highest incidences of skin cancer, also have some of the lowest death rates due to high levels of health expenditure."

By contrast, countries like Pakistan and Bangladesh, which had some of the lowest incidences of skin cancer, had some of the highest mortality rates for skin cancer and lowest levels of overall

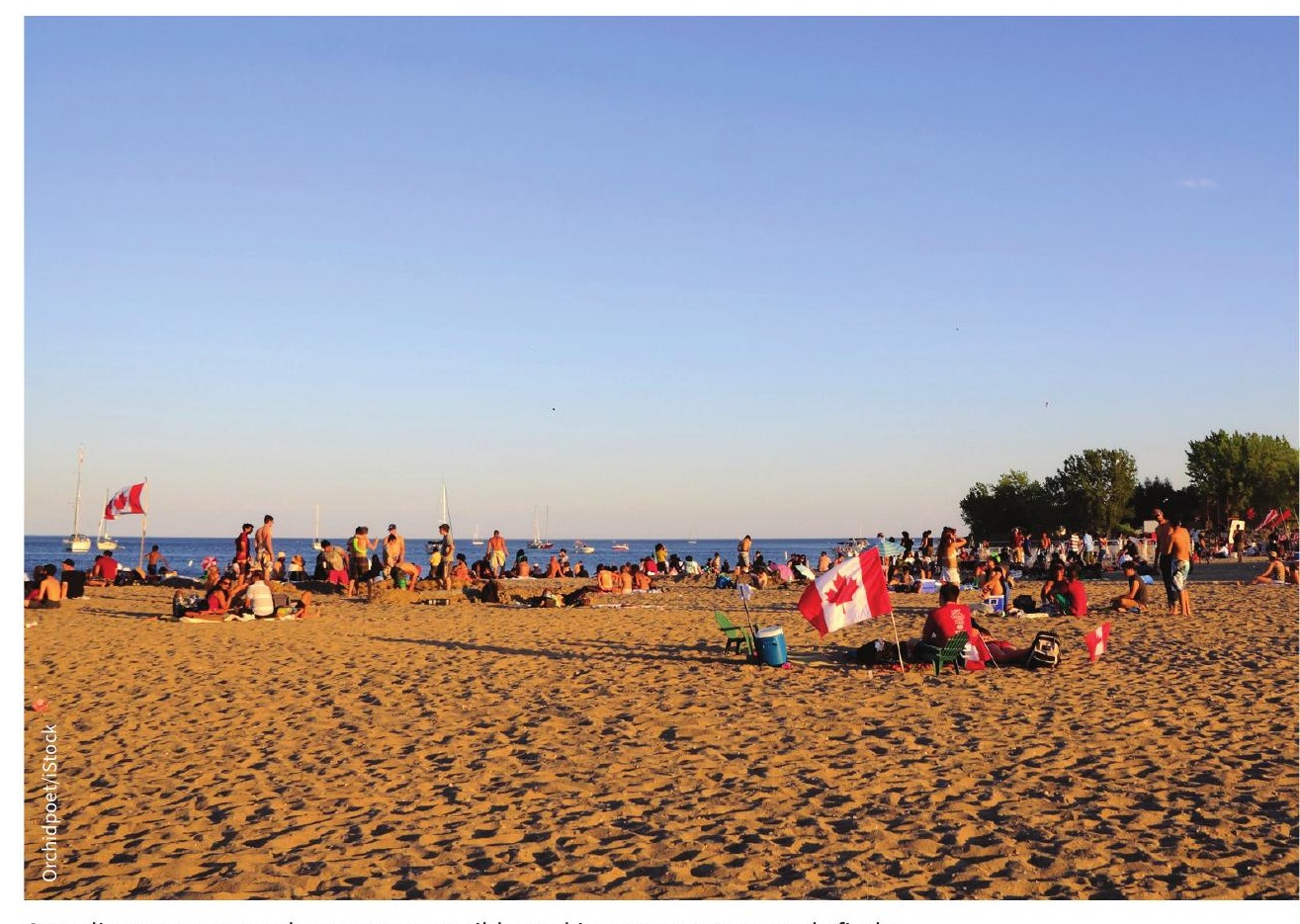

Canadians are among the most susceptible to skin cancer, a new study finds.

health spending. Nigeria had the highest mortality rate at $67 \%$, while Australia had the lowest at $13 \%$.

Canada ranked 8th among the countries with the highest national health expenditures, after the United States, Switzerland, Norway, Sweden, Denmark, the Netherlands and Austria. However, it had a higher mortality rate for skin cancer than many of its international peers, at $21 \%$.
According to the researchers, the study highlights the importance of efficient access to treatment. "Adequate health care spending appears to be effective in keeping the mortality rate lower than in countries with fewer diagnoses and less funding for skin cancer prevention," they concluded.

\section{Lauren Vogel, CMAJ}

